\title{
Novas espécies de Monostylis Tulasne (Podostemaceae) para a região Amazônica
}

\author{
Aldaléa Sprada Tavares ${ }^{1}$ \\ Rafael Trevisan ${ }^{1 *}$ \\ Fernando A. Ferreira ${ }^{2}$ \\ ${ }^{1}$ Departamento de Botânica, Centro de Ciências Biológicas \\ Universidade Federal de Santa Catarina, Campus Universitário Reitor João David Ferreira Lima, Trindade, \\ CEP 88040-960, Florianópolis - SC, Brasil \\ ${ }^{2}$ Universidade Federal de Mato Grosso do Sul, Departamento de Botânica \\ Avenida Senador Filinto Müller, s.n., CEP 79080-190, Campo Grande - MS, Brasil \\ * Autor para correspondência \\ rftrevisan@yahoo.com.br
}

Submetido em 06/03/2015

Aceito para publicação em 11/06/2015

\section{Resumo}

Monostylis Tulasne (Podostemaceae) era um gênero até então monospecífico, contando apenas com $M$. capillacea Tulasne. No entanto, no decorrer de expedições de campo e análise de amostras provenientes da região Amazônica identificamos três novas espécies para o gênero, Monostylis aripuanensis, M. goeldiana e M. paraensis. O presente trabalho traz descrições morfológicas detalhadas, ilustrações, dados sobre o habitat, comentários taxonômicos comparativos e uma chave dicotômica para distinção entre as espécies.

Palavras-Chave: Macrófitas aquáticas; Malpighiales; Reófita; Taxonomia

\section{Abstract}

New species of Monostylis Tulasne (Podostemaceae) from the Amazonian region. Until now, Monostylis Tulasne (Podostemaceae) was considered monospecific, containing only M. capillacea Tulasne. However, recent field expeditions and an analysis of samples from the Amazonian region revealed three new species, Monostylis aripuanensis, M. goeldiana and M. paraensis. The present paper provides detailed morphological descriptions, illustrations, habitat data, comparative taxonomic comments and a dichotomous key to the species.

Key words: Aquatic macrophytes; Malpighiales; Rheophyte; Taxonomy

\section{Introdução}

A família Podostemaceae conta com aproximadamente 54 gêneros e cerca de 300 espécies de plantas reofíticas com distribuição pantropical com extensão em regiões subtropicais (KOI et al., 2012). No Brasil a família está representada por 16 gêneros e 87 espécies (BOVE, 2014).
Apesar de a Amazônia apresentar o maior número de espécies desta família, quando comparada a outras regiões do mundo, ainda pouco se conhece sobre a diversidade e importância ecológica das espécies para os ecossistemas encachoeirados. Tavares (1997) e Tavares et al. (2006), em estudos de campo, constataram a importância das espécies de Podostemaceae na 
manutenção das diferentes associações com a fauna aquática e terrestre em rios amazônicos.

Monostylis Tulasne, até então considerado um gênero monospecífico (M. capillacea Tulasne), foi circunscrito inicialmente pelo conjunto de caracteres principais como tépalas 2, filiformes; estames 1; ovários com ginóforo, estigmas 2, lineares; frutos compressos, elípticos a lanceolados com 14 costelas (TULASNE, 1852). Apresenta ocorrência atual em várias bacias de rios amazônicos localizadas abaixo de $2^{\circ}$ de latitude sul (PHILBRICK et al., 2010), ocorrendo em áreas de cachoeiras e corredeiras.

Em estudo recente sobre a filogenia de Podostemaceae, Tippery et al. (2011), utilizando dados moleculares e morfológicos, constataram que Monostylis está posicionado em um clado formado por vários gêneros morfologicamente distintos, incluindo membros de Apinagia Tul., Jenmaniella Engl., Lophogyne Tul. e Marathrum Humb. \& Bonpl. Todavia, esses autores salientaram a necessidade de uma amostragem de táxons adicionais e busca por maiores evidências moleculares e morfológicas para esclarecer a relação de parentesco entre os gêneros em toda a filogenia da família.

Com ampliação recente de coletas e análise de materiais provenientes de diferentes rios amazônicos, foi possível constatar três novas espécies de Monostylis, as quais são descritas e ilustradas neste trabalho. Além disso, são fornecidos dados sobre o habitat, comentários comparativos e uma chave dicotômica para distinção entre as espécies.

\section{Tratamento taxonômico}

1. Monostylis aripuanensis A. S. Tavares, nov. sp. Tipo. Brasil. Mato Grosso: Aripuanã, rio Aripuanã, cachoeira de Dardanelos, próximo ao paredão, 1009'50,5"S 59²7'20,4”'W, 14. VII. 2007, A. S. Tavares 982 (holótipo, FLOR; Isótipos, INPA; MG) (Figuras 1F, G, H; 2A, B, C, E, G; 3A, B, C).

Monostylis capillaceae Tul. similis, sed ab ea herbis $20-50 \mathrm{~cm}$ altis (non 2-3 cm alt.), foliis segmentis terminalibus espatulatis, crassis, floribus in ramis apicibus dilatatis, staminibus 2, rare 3 (non 1 stamine), ovario majore (5-10 $\mathrm{mm}$ vs. 2-3 mm), fructu 8-costatis in quaque valva (vs. fructu 7 -costatis in quaque valva) differt.

Ervas 20-50 cm compr., com caules achatados, tortuosos, flexíveis. Folhas nas extremidades dos caules, até $5 \mathrm{~cm}$ compr., com pecíolos distintos, segmentos dicotômicos achatados, últimas divisões espatuladas, crassas. Espatelas claviformes, pedicelos filiformes de 10-22 mm. Flores solitárias, nas extremidades de ramos flabelados e crassos; tépalas 3 (-4), 3-4 mm compr., filiformes. Estames 2(-3), iguais, livres, filetes subulados, 6-10 mm compr., anteras 4-6 x $1 \mathrm{~mm}$, oblongas, ápices agudos, base sagitada, rimosa, latrorsa, helicantera após a deiscência. Ovário compresso, 5-10 x 1,5-2,0 mm, estipitado, estípite 1,5-2 mm compr., lanceoloide, ápice truncado, carpelos iguais, 8 costelas por valva, visíveis mesmo quando jovens. Estiletes 2, livres, cilíndricos, filiformes, com ápice bífido. Frutos 6-10 x 1,5-2 mm, ápice truncado, fortemente compressos, com costelas marcadas, inconspícuas no estípite. Sementes $0,2 \mathrm{~mm}$ compr., ovoides.

Distribuição geográfica e ecologia: Conhecida somente para a bacia do rio Aripuanã, entretanto, devido à frequência apresentada pela espécie na área amostrada, acredita-se que a mesma possa ocorrer em bacias hidrográficas próximas. A floração da espécie está relacionada aos ciclos de cheias dos rios e o de chuvas localizadas, florescendo sempre quando o volume d'água está mais baixo, garantido a emersão das flores.

Parátipos: Brasil. Mato Grosso: Aripuanã, rio Aripuanã, próximo ao centro de Humboldt, 16. X.1973, C.C. Berg et al. P18570 (INPA; MG), Aripuanã, próximo à cachoeira de Dardanelos, 16.VI. 2006, A.S. Tavares \& N. Hamada 983 (FLOR); rio Aripuanã, Balneário Oásis, 26.VI.2006, A.S. Tavares \& N. Hamada 984 (FLOR). Rio Aripuanã, abaixo da Cachoeira Dardanelos, 15.VII.2007, A.S. Tavares 985 (FLOR, INPA); Rio Aripuanã, Cachoeira Andorinha, 15.VII.2007, A.S. Tavares 986 (FLOR). 
FIGURA 1: Monostylis goeldiana (Rosa \& Santos 2030, MG). A. Hábito de uma planta. B. Flor em antese. C. Detalhe do androceu. D. Detalhe da antera. E. Fruto; Monostylis aripuanensis (Tavares 982, FLOR). F. Hábito. G. Detalhe das terminações foliares. H. Flor em antese, com detalhe do ápice estigmático bífido; Monostylis capillacea (Tipo: Spruce 1038, P). I. Hábito. J. Flor em antese; Monostylis paraensis (Rosa et al. 4619, FLOR). K. Hábito, sobre substrato, em frutificação. L. Flor em antese.

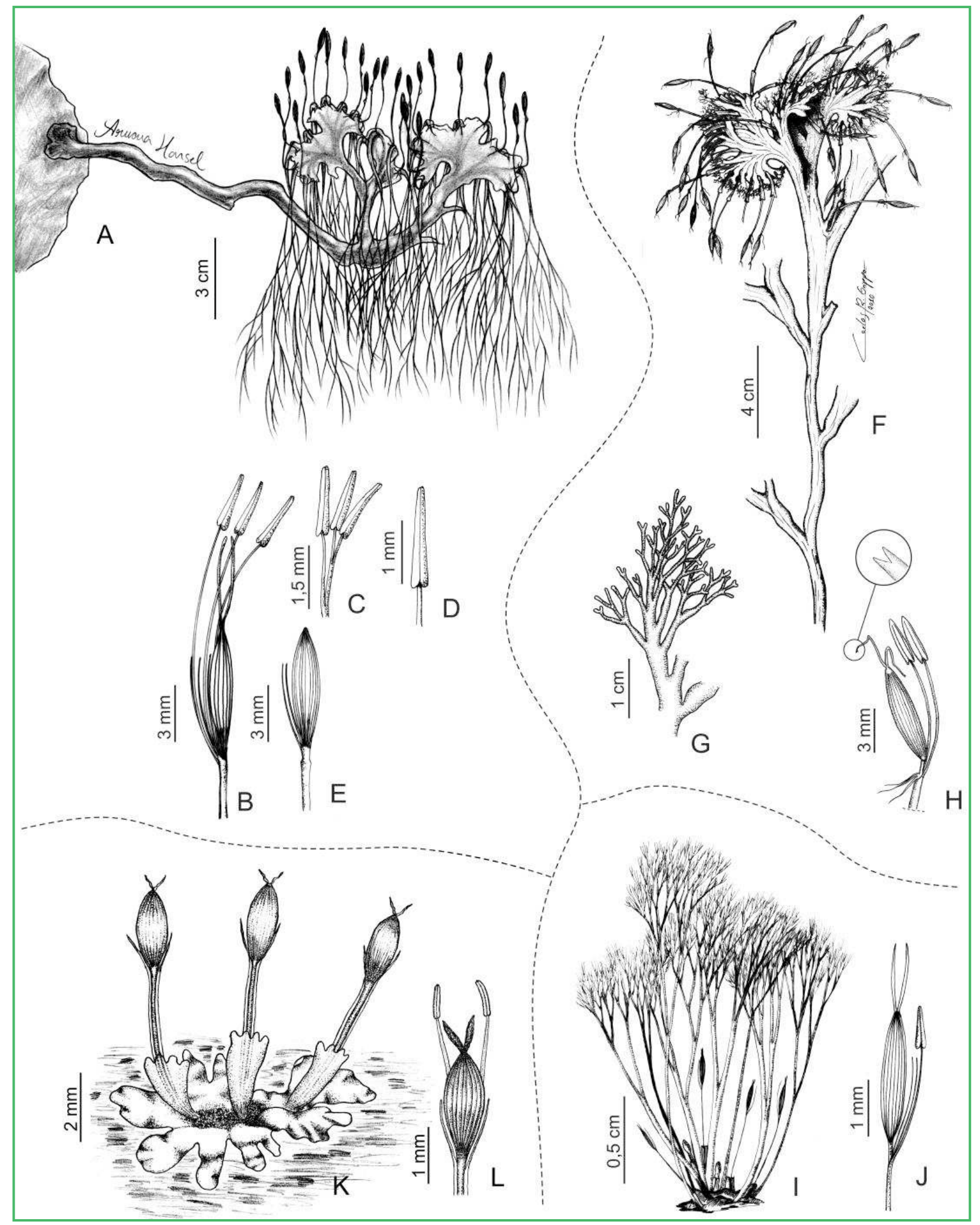


FIGURA 2: Monostylis aripuanensis. A. Aspecto geral da planta viva em seu habitat. B. Flores em antese. C. Detalhe das flores e das extremidades das folhas. E. Fruto. G. semente ovoide. Monostylis goeldiana F. Fruto. H. semente ovoide. Monostylis paraensis D. Fruto. I. semente orbicular [E e G - Tavares 986 (FLOR); F e H - Tavares \& Flausino Jr. 987 (FLOR); D e I - Rosa et al. 4619 (MG)].

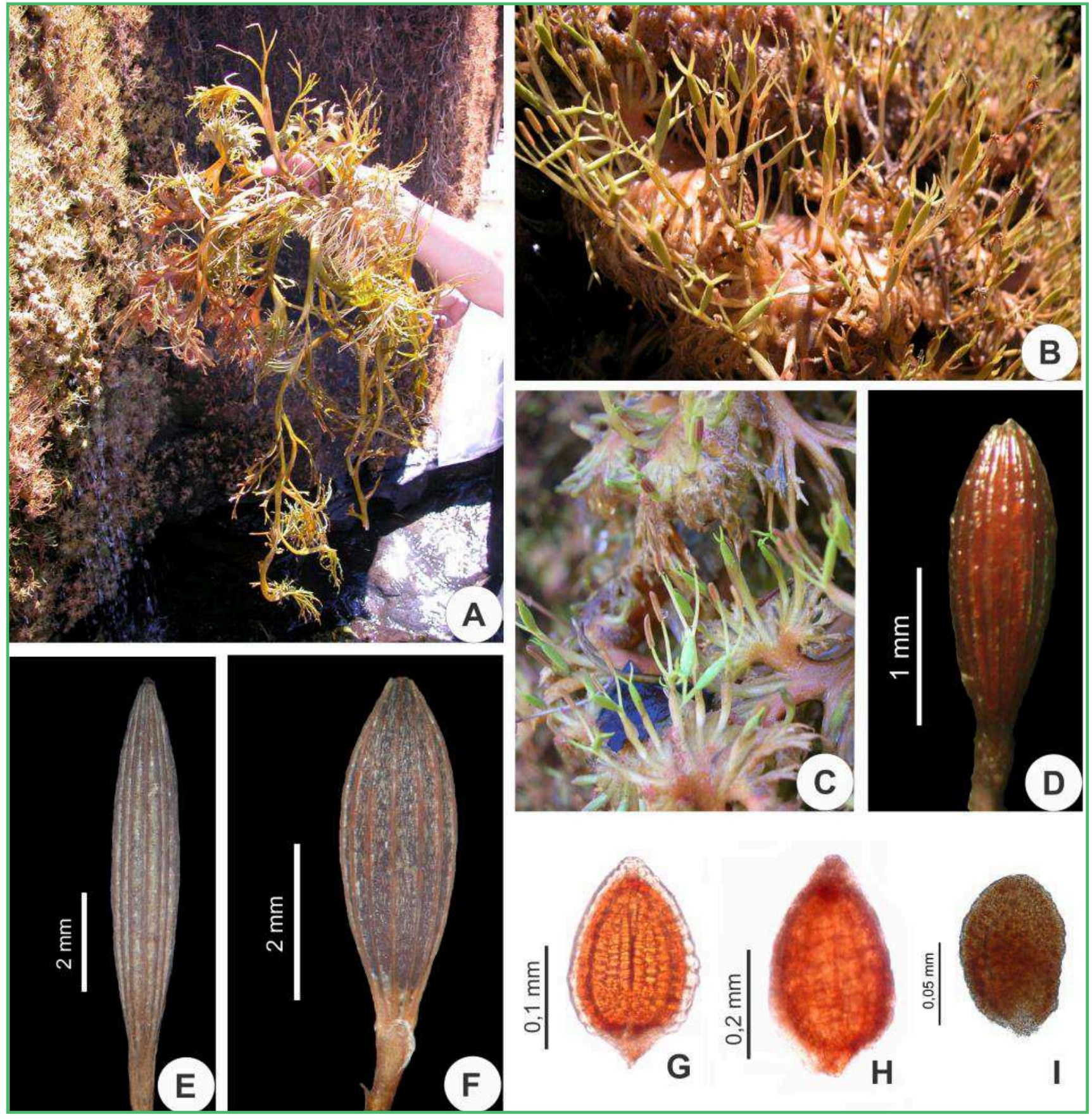


FIGURA 3: Monostylis aripuanensis. A. Crescendo fixa no paredão da cachoeira Andorinha, rio Aripuaná, MT. B. Plantas ao longo da cachoeira em processo de senescência. C. População crescendo sob influência do borrifo da cachoeira. Monostylis capillacea. D. População de crescendo sobre rochas próximo à localidade tipo, rio Tapajós, Santarém, PA. Fotos: A-C: Neusa Hamada; D: F. Ferreira.
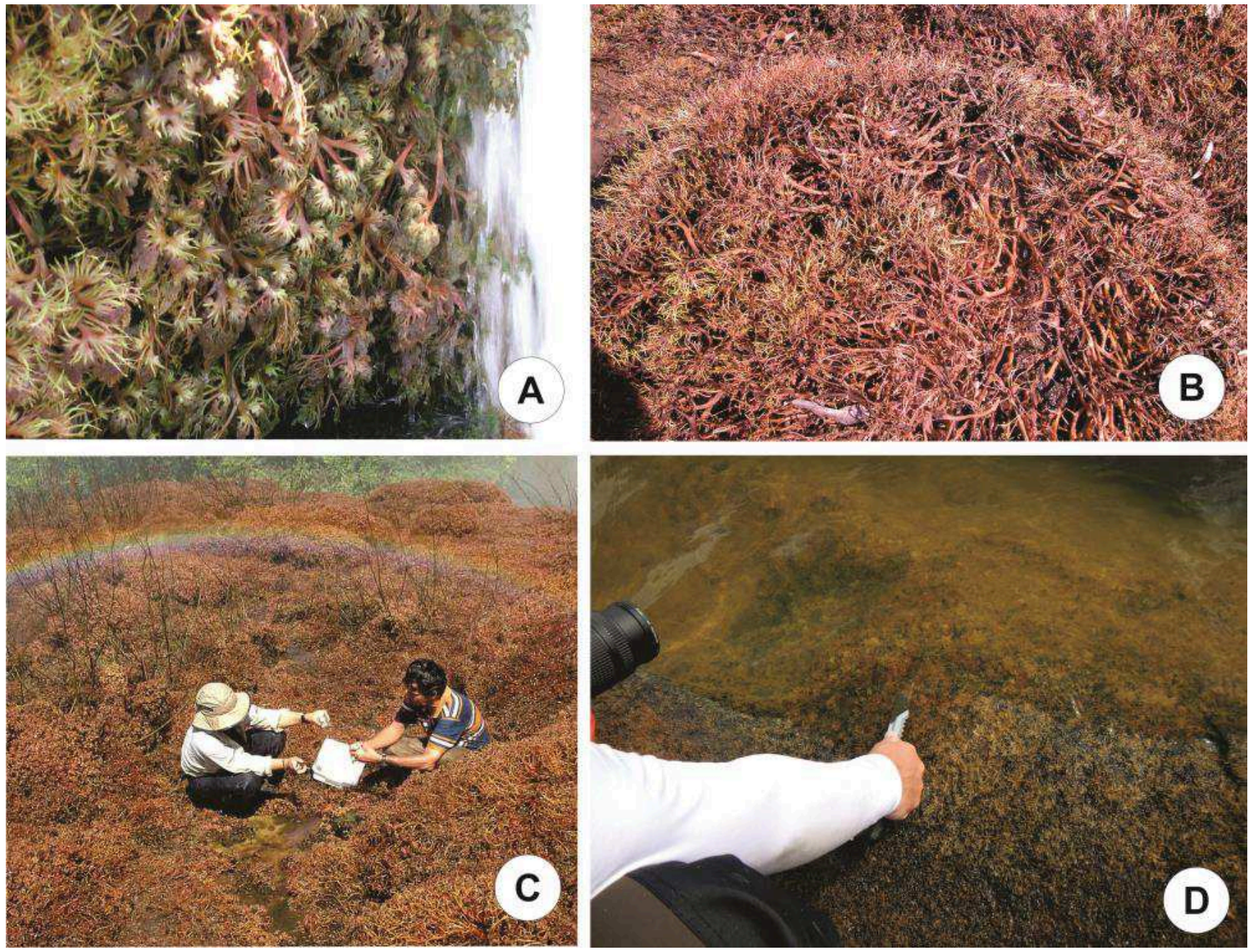

Etimologia: O nome foi escolhido em referência ao rio onde o holótipo foi coletado.

Comentários: $\mathrm{O}$ novo táxon pode ser facilmente diferenciado de Monostylis capillacea (Figuras $1 \mathrm{I}$, J; 3D) pelo tamanho, ramos longos folhosos, folhas com segmentos terminais espatulados e crassos ( $v s$. plantas pequenas, folhas basais aderidas ao substrato, pecioladas e filiformes), flores solitárias em grande número no ápice dos ramos, 2 estames, raro 3, e pelo ovário muito maior (5-10 mm vs. 2-3 mm).

2. Monostylis goeldiana A. S. Tavares, nov. sp. Tipo. Brasil. Mato Grosso: Juruena, margem direita da cachoeira de Salto Augusto, rio Juruena, 853'06,3"S 58³3'24,9'W, 28.V. 1977, N. A. Rosa \& M. R. Santos 2030 (holótipo, MG 54300; Isótipo, INPA 214760) (Figuras 1A, B, C, D, E; 2F, H).

Monostylis capillaceae Tul. similis, sed ab ea herbis 10-20 cm altis (non 2-3 cm alt.), foliis longioribus, filiformibus, floribus in ramis apicibus dilatatis, staminibus 2-3 (non 1 stamine), conatis in basibus vel liberis, ovario majore (3-7 $\mathrm{mm} v s .2 \mathrm{~mm})$, fructu ellipsoidali, subcompresso, 6-costatis in quaque valva (vs. fructu angusto-ellipsoidali, compresso, 7-costatis in quaque valva) differt. 
Ervas 10-20 cm compr., com caules subcilíndricos, tortuosos, rígidos. Folhas nas extremidades dos caules, 5-20 cm compr., com pecíolos distintos, segmentos longo filiformes, dicotômicos, últimas divisões filiformes, membranáceas. Espatelas claviformes, pedicelos filiformes de 10-20 mm. Flores solitárias, na extremidade crassa dos ramos; tépalas 3-4, lineares, praticamente da altura do ovário. Estames 2-3, ligeiramente adelfos na base ou livres, filetes filiformes, 10-13 mm compr., anteras sagitadas, ápices obtusos, base aguda a ligeiramente obtusa, rimosa, latrorsas. Ovário, 3-5(7) x 1,5-2,0 mm, estipitado, estípite 2-4 mm compr, elipsoidal, ligeiramente compresso, ápice agudo, carpelos iguais, 6 costelas por valva, conspícuas mesmo quando jovens. Estiletes 2, livres, cilíndricos, filiformes com ápice agudo. Fruto similar ao ovário, ápice truncado, com costelas marcadas que se prolongam no estípite de forma conspícua pela degeneração do tecido parenquimático. Sementes 0,4 mm compr., ovoides.

Distribuição geográfica e ecologia: Espécie até o momento conhecida somente da localidade tipo, entretanto acredita-se que a mesma possa ocorrer em outras áreas lóticas ao longo do rio Juruena ou em bacias de rios próximos. Da mesma forma que Monostylis aripuanensis, $M$. goeldiana tem floração relacionada aos ciclos de cheias dos rios e de chuvas localizadas.

Parátipo: Brasil. Mato Grosso: Juruena, Salto Augusto, rio Juruena, 15. VIII. 2007, A.S. Tavares \& N. Flausino Jr. 987 (FLOR).

Etimologia: O nome da espécie é em homenagem ao naturalista e zoólogo alemão-suíço, Emílio Augusto Goeldi, o qual teve grande importância nos estudos sobre a biodiversidade amazônica no final do século XIX e início do século XX.

Comentários: O novo táxon pode ser facilmente diferenciado de Monostylis capillacea (Figuras $1 \mathrm{I}$, J; 3D) pelo tamanho, ramos e folhas muito mais longas, filiformes, flores no ápice dos ramos, 3 estames, parcialmente adelfos ou livres ( $v s .1$ estame), pelo ovário maior (6-7 mm vs. 2-3 mm) e pelo fruto elipsoide, ligeiramente compresso com 6 costelas por valva (vs. fruto estreitamente-elíptico, compresso com 7 costelas por valva).
3. Monostylis paraensis A. S. Tavares, nov. sp. Tipo. Brasil. Pará: Marabá, rio Itacaiunas, Serra Norte, abaixo de Caldeirão, 5’52'32,4"S 50²9'23,9"W, 16. VIII.1984, N. A. Rosa \& M. F. Silva R.P Bahia, M.R. Santos 4619 (holótipo MG 112410; Isótipo FLOR) (Figuras $1 \mathrm{~K}, \mathrm{~L}$; 2 D, I).

Monostylis capillaceae Tul. similis, sed ab ea foliis segmentis planis lanceolatis vel oblongis (vs. segmentis filiformibus), fructu ellipsoidali, subcompresso, 8-10-costatis in quaque valva (vs. fructu angustoellipsoidali, compresso, 7-costatis in quaque valva) differt.

Ervas 0,7-1,5 cm compr., aderidas ao substrato, acaules, base rígida. Folhas basais, 0,7-1,5 cm compr., pecíolos indistintos, segmentos planos lanceolados a oblongos, ápice obtuso a agudo, 1-3 vezes dicotômicos. Espatelas claviformes, pedicelos filiformes de 4,0-5,0 $\mathrm{mm}$, alados em toda a extensão. Flores solitárias, basais ou axilares; tépalas 2, $1 \mathrm{~mm}$ compr., lineares. Estames 2, ultrapassando o ovário em altura, filetes membranáceos livres, $3 \mathrm{~mm}$ compr., anteras oblongas, ápices obtusos, base obtusa, rimosas, latrorsas. Ovário 1,5-2 x 0,8-1 $\mathrm{mm}$, ligeiramente estipitado, estípite $0,5 \mathrm{~mm}$, elipsoidal, levemente compresso, ápice arredondado, carpelos iguais, 8-10 costelas por valva, visíveis mesmo quando jovens. Estiletes 2, $1 \mathrm{~mm}$ compr., livres, filiformes, estreitando em direção ao ápice, agudo. Fruto similar ao ovário, ápice truncado, 1,5-2,0 x $1 \mathrm{~mm}$, elipsoides. Sementes $0,1 \mathrm{~mm}$ compr., orbiculares.

Distribuição geográfica e ecologia: Espécie até o momento conhecida somente da localidade tipo, entretanto, acredita-se que a mesma possa ocorrer em outras áreas lóticas ao longo do rio Itacaíunas, afluente do rio Tocantins, em áreas próximas a cidade de Marabá, estado do Pará. Da mesma forma que as espécies anteriores, tem floração relacionada aos ciclos de cheias dos rios e de chuvas localizadas.

Etimologia: O nome da espécie foi atribuído ao estado onde foi coletado o exemplar tipo.

Comentários: Monostylis paraensis pode ser facilmente diferenciado de M. capillacea (Figuras 1 I, J; 3D) pela terminação das folhas lanceoladas a oblongas (vs. segmentos filiformes) e pelos frutos elipsoides com 8-10 costelas por valva, enquanto que $M$. capillacea 
apresenta frutos estreito-elipsoides, com 7 costelas por valva.

O formato de fruto de $M$. paraensis assemelha-se ao fruto de $M$. goeldiana, mas difere desta não só pelo menor tamanho do fruto $(1,5-2,0 \times 1 \mathrm{~mm} \mathrm{vs.3-5(7) \times}$ $1,5-2,0 \mathrm{~mm})$ e maior número de costelas (8-10 costelas por valva vs. 6 costelas por valva), mas também pela forma e tamanho das demais estruturas vegetativas (planta acaule, 0,7-1,5 cm, segmento foliares lanceolados a oblongos vs. planta caulescente, 10-20 cm compr., segmentos foliares filiformes).

\section{Chave para separação das espécies de Monostylis Tulasne}

1. Plantas acaules, folhas basais, 0,7-3 cm compr., terminações capiláceas, lanceoladas a oblongas; 2 tépalas, 1-2 estames; ovário de 2-3 mm compr. ........2

2. Segmentos foliares capiláceo; folhas pecioladas; 1 estame; ovário sublanceolado, compresso; estigma espatulado; fruto com 7 costelas por valva; pedicelo não alados M. capillacea

2'. Segmentos foliares lanceolados a oblongos; folhas sem pecíolo; 2 estames, ovário elipsoidal, levemente compresso; estigma linear; fruto de 8-10 costelas por valva; pedicelos alados

M. paraensis

1'. Plantas caulescentes, folhas na extremidade de caules, terminações filiformes ou espatuladas; 3-4 tépalas; 2-3 estames; ovário 3-10 mm compr. ...3

3. Folhas $5-15 \mathrm{~cm}$ compr., terminações filiformes; caules subcilíndricos; ramos do estilete com ápice agudo; sementes de $0,4 \mathrm{~mm}$ compr. M. goeldiana

3'. Folhas até $5 \mathrm{~cm}$ compr., terminações espatuladas; caules achatados; ramos do estilete com ápice bífido; sementes de 0,2 mm compr.

M. aripuanensis

\section{Status de conservação das novas espécies}

As espécies da família Podostemaceae, por vegetarem em ambientes lóticos, são extremamente sensíveis a quaisquer mudanças físico-químicas das águas. Suas populações são facilmente afetadas pelas mudanças no ambiente, principalmente aquelas de origem antrópica. A necessidade de águas limpas e oxigenadas para manter as populações, torna as espécies e suas interações biológicas associadas vulneráveis e diretamente impactadas pelas construções de hidrelétricas e/ou represamento de cachoeiras e corredeiras.

O enquadramento das novas espécies de Monostylis nos critérios da IUCN (2014) para avaliação do grau de ameaça das espécies é difícil, principalmente considerando que os rios amazônicos ainda não foram suficientemente amostrados para se definir qual o número e o tamanho das populações, o que poderia levar ao equívoco de enquadrar as novas espécies como Deficiência de Dados (Data Deficient-DD).

Todavia, considerando a fragilidade dos ecossistemas onde as espécies ocorrem, e também que a maioria das espécies está restrita a um único rio e/ou afluentes, acredita-se que as novas espécies deveriam ser consideradas na categoria Vulnerável (VU) ou pelo menos Quase Ameaçado (NearThreatened - NT).

\section{Agradecimentos}

Os autores agradecem a J. Fontoura e C. Grippa pela elaboração das ilustrações e a profa. Dra. Marlene Freitas da Silva (in memoriam), grande incentivadora de estudos taxonômicos das espécies amazônicas.

\section{Referências}

BOVE, C. P. Podostemaceae. Lista de espécies da flora do Brasil. 2014. Disponível em: <http://floradobrasil.jbrj.gov.br/jabot/ floradobrasil/FB194>. Acesso em: 22 nov. 2014.

IUCN. Guidelines for using the IUCN red list categories and criteria, version 11. Prepared by the Standards and Petitions Subcommittee. 2014. Disponível em: < http://www.iucnredlist.org/ documents/RedListGuidelines.pdf $>$. Acesso em: 28 maio 2014.

KOI, S.; KITA, Y.; HIRAYAMA, Y.; RUTISHAUSER, R.; HUBER, K. A.; KATO, M. Molecular phylogenetic analysis of Podostemaceae: implications for taxonomy of major groups. Botanical Journal of the Linnean Society, London, v. 169, p. 461-492, 2012.

PHILBRICK, C. T.; BOVE, C. P.; STEVENS, H. I. Endemism in Neotropical Podostemaceae. Annals of the Missouri Botanical Garden, St. Louis, v. 97, p. 425-456, 2010. 
TAVARES, A. S. Podostemaceae de alguns rios de água preta do estado do Amazonas. 1997. 216 f. Tese (Doutorado em Botânica) - Instituto Nacional de Pesquisas da Amazônia/Fundação Universidade do Amazonas, Manaus. 1997.

TAVARES, A. S.; COLLART, O. O.; ENRICONE, A. A família Podostemaceae em rios amazônicos e comunidades de insetos associados. Ínsula, Florianópolis, v. 35, p. 19-50, 2006.

TIPPERY, N. P.; PHILBRICK, C. T.; BOVE, C. P.; LES, D. H. Systematics and phylogeny of Neotropical Podostemaceae. Systematic Botany, Laramie, v. 36, p. 105-118, 2011.

TULASNE, L. R. Monographia Podostemacearum. Archives du Museum d'Histoire Naturelle, Paris, v. 6, p. 1-208, 1852. 